\title{
Klimawandel - eine Herausforderung für die BWL
}

\author{
Edeltraud Günther $\cdot$ Rainer Souren
}

Online publiziert: 2. März 2010

(C) Springer-Verlag 2010

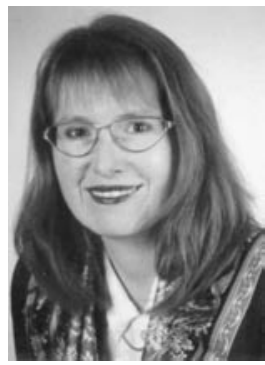

Edeltraud Günther

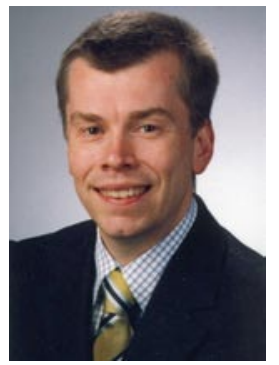

Rainer Souren

Der Klimawandel stellt in zweierlei Hinsicht eine Herausforderung für die Unternehmen und damit die betriebswirtschaftliche Forschung dar: Einerseits führen veränderte Klimabedingungen zu direkten Effekten auf die Unternehmen. Diese können als Niveaueffekte in Form von Mittelwertveränderungen (z. B. Niederschlagsmenge) oder Stabilitätsveränderungen in Form von Varianzschwankungen (z. B. Extremwetterereignisse) unternehmerische Anpassungen erforderlich machen (Schlagwort: Adaptation). Andererseits führt der Klimawandel zu veränderten politischen Rahmenbedingungen, aber auch Märkte und

Prof. Dr. E. Günther $(\bowtie)$

Fakultät Wirtschaftswissenschaften,

Lehrstuhl für Betriebswirtschaftlehre,

insbesondere Betriebliche Umweltökonomie,

Technische Universität Dresden, Münchner Platz 1/3,

01187 Dresden, Deutschland

E-Mail: bu@mailbox.tu-dresden.de

Prof. Dr. R. Souren

Fachgebiet Produktionswirtschaft/Industriebetriebslehre,

Technische Universität Ilmenau, Postfach 100565,

98684 Ilmenau, Deutschland

E-Mail: rainer.souren@tu-ilmenau.de

Investoren fragen immer häufiger nach der Klimarelevanz von Unternehmen. Hierbei steht der Beitrag der Unternehmen zum Klimawandel im Zentrum der Betrachtung (Schlagwort: Mitigation). Diese Ausgabe des Umweltwirtschaftsforums widmet sich beiden Anpassungserfordernissen. Die Beiträge dieses Hefts fassen die Vorträge und Diskussionen einer Tagung zum Thema „Klimawandel Eine Herausforderung für die BWL“" zusammen, an der 15 Professoren, 11 doctores und 30 Nachwuchswissenschaftler teilnahmen. Sie fand auf Einladung des Lehrstuhls für Betriebliche Umweltökonomie der TU Dresden und der Wissenschaftlichen Kommission „Nachhaltigkeitsmanagement" im Verband der Hochschullehrer für Betriebswirtschaft am 5. und 6. Oktober 2009 in Dresden statt. 